\title{
ELS BURGÈS, UNA FAMÍLIA DE MERCADERS A LA RECERCA DE L'ASCENS SOCIAL'
}

\author{
DOLORS SANAHUJA I TORRES \\ Institut d'Ensenyament Secundari "Les Marines" \\ Castelldefels (Barcelona)
}

\begin{abstract}
SUMARI
1. Els origens familiars.- 2. Els fills de Guillem Burgès.- 3. Els néts i nêtes del patriarca.- 4. El besnéts accedeixen a la cort.- 5. Els Burgès en el conflictiu segle XV.- 6. Els darrers Burgès de Sant Climent.
\end{abstract}

\section{ELS ORÍGENS FAMILIARS}

L'article que presentem té com a protagonistes una extensa família, la dels Burgès, senyors de Viladecans i Gavà (Baix Llobregat) des de mitjan segle XIII; una família que pot servir-nos com a exemple de moltes altres perquè la seva vida i la seva evolució reflecteixen els anhels, lluites similars per obrir-se camí en la societat barcelonina baixmedieval. L'estudi d'aquest procés ens sembla especialment interessant perquè hem pogut analitzar els diferents mecanismes emprats per obtenir puixança econòmica i millor consideració social $i$, a la vegada, ens ha estat possible resseguir les traces

\footnotetext{
'Les abreviatures utilitzades en aquest article són les següents: $A C A=A r x i u$ de la Corona d'Aragó (Barcelona): $\mathrm{ACB}=$ Arxiu de la Catedral de Barcelona; $\mathrm{ABE}=$ Arxiu de la Baronia d'Eramprunyà (arxiu privat); AHPNB =Arxiu Històric de Protocols Notarials de Barcelona; $\mathrm{AMV}=$ Arxiu Municipal de Viladecans; $\mathrm{BC}=$ Arxiu de la Biblioteca Nacional de Catalunya.

"Anuario de Isstudies Medievales". 27 (1997)
} 
dels primogènits d'aquesta família fins a la seva extinció biològica, passada la porta d'accés a l'Edat Moderna.

Les notícies més remotes respecte de la família dels Burgès les localitzem a mitjan segle XIII sota el regnat de Jaume I. El cognom Burgès figura enregistrat l'any $1227^{2}$ quan Berenguer Burgès, com a veguer de Barcelona, nomenà Sibil·la, vídua de Pere Grony, tutora dels fills nascuts del matrimoni. Uns anys després, la mateixa font documental, ens notifica com Pere Burgès signà un debitori de deu morabatins a favor de Crespí, jueu. També les Rúbriques de Bruniquer recullen la presència d'aquest cognom en els llargs llistats dels Consellers de la Ciutat de Barcelona durant aquell segle: el 1253 citen Vidal Burgès, el 1257, Guillem Burgès, el 1285 constava Bernat Burgès, el 1292 Pere Burgès i el 1295 hi trobem Guillem Pere Burgès ${ }^{3}$.

El fil de l'estructura familiar el comencem a resseguir a partir de Guillem i Bartomeu Burgès, germans, maridats respectivament amb Maria i Blanca. Ambdues famílies vivien per la zona comercial de Santa Maria del Mar, prop de la plaça de la Bòria, una plaça que havia estat per Berenguer Pelegrí cap a la primera meitat del segle XIII i inscrita en un barri artesà per excel·lència ${ }^{4}$.

La casa ${ }^{5}$ de Bartomeu Burgès ens confirma l'ofici de mercaders de la família. A la planta baixa de l'habitatge hi tenien una botiga, situada sota l'escala de la casa. Aquesta botiga comptava amb un respectable nombre d'estris relacionats amb la venda del vi. Se'ns parla de deu gerres de terra buides i gerres petites, se'ns enumeren quatre embuts per a mesurar, dos calastrons de ferro i un de fusta, dos recipients, dos cups grans i quatre de

\footnotetext{
'ACB 1-7-1694.

${ }^{3}$ Cognoms similars a Burgès, com Burget, Brugués. Bruguera, els llegim en documents del mateix període i cal anar amb compte per no confondre'ls. Tanmateix no és clar que només hi hagués uns Burgès perquè ens sembla que els citats Bartomeu i Vidal Burgès gaudien d'una posició social superior als Burgès que hem estudiat. Per altra banda, el seu prenom no fou posat a cap membre de la família, quan la repetició dels prenoms masculins era un recurs de llinatge insistentment utilitzat.

${ }^{4}$ Carme BATLLE, La casa burgesa en la Barcelona del segle XIII, "La societat barcelonina a la Baixa Edat Mitjana". ("Acta Historica et Archaeologica Mediaevalia"), Annex 1, pp. 9-51. Universitat de Barcelona, 1983.

${ }^{5}$ Fou la vídua de Bartomeu qui ordenà aixecar inventari de tots els béns mobles i immobles per evitar malentesos posteriors, segons Blanca deixà especificat. Esperem publicar aviat Yinventari complet d'aquesta vivenda familiar. ACB, Notari Bernat de Vilarrúbia, Manual de 1310 , fols. $126 \mathrm{v}-132 \mathrm{v}$.
} 
petits, dos barrils de celler i tres barrilets, dotze bótes entre grans i mitjanes, una portadora gran i dues de mitjanes i mesures de fusta $\mathrm{i}$ de terra, totes elles aptes per mesurar el vi. La casa, que comprenia planta baixa, planta pis i golfes, guardava en la part més alta de l'habitatge, l'habitació/torre, estris complementaris de la botiga com dotze gerres de terra buides i tres recipients de celler. La família potser participava també en la incipient indústria del cotó i de l'espart perquè entre els objectes de la casa hi havia balances, peses i calestrons i els manats de fil de lli, d'estopa i de cotó es trobaven amuntegats en capses de fusta ubicades en diferents cambres de la casa, així com també una sèrie d'eines per treballar-los com torns de filar cotó, cardes de ferro per pentinar la llana i diverses mesures de fusta. També a la sala principal de la casa es guardaven, dins una bossa de pell, tres balances de coure amb el seu estoig $i$ vàries petites peces del mateix metall amb una peça anomenada march, pes equivalent a la meitat d'una lliura, i que s'usava per a pesar or i argent; era el patró i la norma segons el qual havien de regularse els pesos i les mesures.

Per altra banda, el testament de Guillem Burgès ${ }^{6}$ recull la voluntat del testador de llegar cinquanta besants per a la redempció de captius, especificant que els diners havien d'ésser per a persones caigudes a mans sarraïnes mentre exercien l'ofici de negociants, de mercaders ("redimant captivos qui inciderint dum exercerent officium negotiacionis").

Ambdós germans eren escollits representants de l'estament de ciutadans honrats de la Ciutat de Barcelona i disposaven, tal i com s'esqueia a la seva posició, del vestuari i armes adequades. Entre la roba arreplegada dins la cambra de Bartomeu, el notari deixà constància de l'existència de dues gramalles, roba d'ús poc freqüent i només habitual entre els que tenien poder municipal i una túnica llarga fins als peus on es combinava el teixit amb pells d'animals. Hi havia també una túnica de tela, una peça que cobria tot el cos i part de les cames i que es posava damunt del que podríem anomenar roba interior; no s'indica el color, però acostumaven a ésser blanques o de color pàllid cru. També hi havia una cota, una mena de variant de túnica, portada tant per homes com per dones, que anava des del coll fins a prop dels peus. Una clàmide, una capa curta que cobria l'esquena i es cordava al coll, era de color viu i duia pells de conill i, completant el vestuari del difunt, una pallissa curta rematada amb una ploma blanca de

"ACB. 4-8-98. 
conill. Quant a armes, l'inventari cita dos esperons, una cota i uns llancers guardats a la torre junt amb dos parells de pitrals de ferro de l'arnès i una sella de cavall amb el senyal del difunt arraconada per la cuina, mentre altres dues selles de muntar, una amb un coixí de color vermell i l'altra amb un coixí de color negre, eren a la sala i dins una caixa. A la cambra del difunt s'hi trobaren un parell de cuixeres, part de l'arnès per cobrir les cames, un parell de guants de ferro, una espasa amb beina i amb guarniment de llautó, un fre de cavall bo, amb corretges per subjectar el cap de l'animal, i corretges de cuir per ornament, tres espases molt velles, un tambor i un perpunt o vestuari militar fet de tela forta repuntejada que es posava damunt de tot de l'armadura i anava des del coll fins a mitja cuixa del guerrer. En definitiva, la caixa contenia part dels elements propis per a la defensa. Recordem, ara que ve al cas, el manament reial obligant a tenir armes a casa, i el deure de tot ciutadà de sortir armat a defensar, si s'esqueia, la seva ciutat.

La família del matrimoni integrat per Bartomeu i Blanca s'estroncà a partir de les primeres dècades del segle XIV, tal vegada afectada pel daltabaix epidèmic iniciat el 1333. Potser la situació econòmica de la família havia anat a mal borràs, potser una malaltia llarga i cara havia enfeblit una bona posició perquè la vivenda recull pocs objectes luxosos tret d'una tassa de plata i d'una copa del mateix metall banyada en or. A més, se'ns diu quela vídua havia empenyorat una altra copa de plata en trencadís per cent onze sous i vuit diners com a mesura per fer front a un deute pendent del marit. No deixa de cridar-nos l'atenció, per exemple, que la majoria de bótes, cups i gerres inventariades fossin buides i que, tot $\mathrm{i}$ que hi ha mobles i roba, s'explicita que tot és gastat i vell i, per arrodonir-ho, se'ns parla del deute pendent entre el difunt $\mathrm{i}$ el seu gendre, Pere Ferrer, en concepte del dot de la seva filla Margarida, un deute que pujava dues-centes lliures.

Guillem Burgès tingué més sort que no pas el seu germà. Quan va morir tenia un consolidat patrimoni, una família continuadora del cognom amb cinc fills mascles (Pere, Jaume, Guillem Pere, Arnau i Andreu) i només una noia (Raimunda) i suficients diners com per ordenar ésser enterrat en el cementiri dels frares franciscans de Barcelona, junt a la capella de Sant Esteve que ell havia fet edificar. A diferència del que ja era usual a l'època, 
la institució d'hereu universal' Guillem repartí la seva heretat quasi de manera proporcionada, especialment entre els tres fills més grans. A Pere li atorgà la Torre de Viladecans ${ }^{8}$ que tenia en franc alou a la parròquia de Sant Climent amb tot el que contenia de terres i béns i amb tots els drets damunt homes i dones. A Jaume li cedí Gavà sota els mateixos termes i condicions, bo i especificant l'àmbit territorial de la donació. A Guillem Pere li transmeté Viladecans, igualment sota idèntics termes, alhora que fixava els límits de la propietat entre la riera de Sant Llorenç i la riera de Sant Climent, el mar i la muntanya. Li traspassava igualment quatre masos situats en el mateix indret $i$ treballats sota règim de tinença per diferents famílies pageses al·ludides com a coloni.

Guillem Burgès havia fet fortuna mercadejant per aquests mons, però els beneficis obtinguts els distribuí en diferents inversions entre les que figuraven les compres de terres. Aquestes inversions representaven una font d'ingressos però, sobretot, eren base de prestigi social. La descoberta del Pla de Barcelona, un cop superada la inseguretat dels temps anteriors, havia abocat als ciutadans barcelonins a interessar-se per aquelles terres que limitaven amb el Llobregat per una banda i amb el Besós per l'altra, seguint les passes de les famílies nobiliars i de les institucions religioses, pioneres en aquells indrets. Guillem Burgès havia comprat la part baixa oriental d'Eramprunyà ${ }^{9}$ al comte-rei Jaume I però no quedà satisfet només amb l'adquisició d'aquella hisenda i, anys més tard, adquirí part dels drets jurisdiccionals damunt el territori, béns i persones de Gavà, Viladecans $i$ Torre Roja. Jaume I li concedí en caràcter hereditari el 13 d'abril del 1265 la facultat de capturar, detenir i condemnar pecuniàriament els homes i dones del seu territori que poguessin cometre delicte; només prohibia aplicar la

\footnotetext{
${ }^{7} \mathrm{Hem}$ constatat la presència de la figura de l'hereu des de mitjan segle XI dins l'estament nobiliari en el territori esmentat del Baix Llobregat.

${ }^{8}$ Comunament coneguda com a Torre Roja o Torre Burgesa a partir de la instal-lació d’aquesta família. L’edifici, arranjat en successives ocasions, havia estat anomenat primigèniament Torre Marcusa i Torre de na Sanxa. Actualment forma part del patrimoni públic de la ciutat de Viladecans.

${ }^{9}$ El terme d'Eramprunyà, un ampli territori situat a l'extrem esquerre del Baix Llobregat, entre el riu i el Garraf, comprenia les parròquies de Sant Cristòfol de Begues. Santa Maria de Castelldefels, Sant Pere de Gavà, Sant Miquel d’Eramprunyà i Sant Climent de Llobregat que. a la vegada, tenia incorporat Viladecans. Aquest espai havia estat dominat durant tota l'Alta Edat Mitjana per la família vescomtal dels Sant Martí, per delegació expressa dels Comtes de Barcelona i pel monestir de Sant Cugat, el qual havia rebut l'encàrrec d'organitzar i repoblar tota la part de la costa. Aquesta estructura de poder es mantingué fins el segle XIII quan la proximitat de la ciutat de Barcelona trastocà l'antic equilibri senyorial.
} 
pena de mort, la mutilació o la destrucció de la persona, però se li reconeixia el dret a imposar multes i el dret d'exigir càrregues tan feixugues per a la pagesia com tragines, joves i altres servituds ${ }^{10}$.

Els altres fills de Guillem Burgès, Andreu, Arnau i Raimunda, reberen també la seva part. A Andreu li cedí unes cases de la seva propietat ubicades en el carrer que menava a mar a Barcelona, més un mas comprat i una vinya amb terra que tenia pel monestir de Sant Llorenç de Munt, situat damunt Santa Anna, és a dir, en els límits de l'actual plaça de Catalunya. A Arnau li donà mil auris i la meitat d'un honor ubicat en el lloc anomenat Codols mentre Raimunda veuria confirmada la seva donació quan es convingués el seu matrimoni.

\section{ElS FILLS DE GUILLEM BuRGÈS}

Els hereus d'aquest mercader orientaren els seus interessos cap a diverses branques productives. Les propietats adquirides pel seu pare eren insuficients, un cop repartides, per a mantenir una posició social de burgesos honorables i, d'aquesta manera, prosseguiren amb la tradició familiar d'invertir i mercadejar per tota la Mediterrània, a la vegada que s'implicaren en la política expansiva mediterrània dels Comtes-reis

Pere Burgès, l'hereu de la Torre Roja de Viladecans, obtingué del monarca Jaume II l'any 1296, junt amb Bernat Marquet, la facultat de cobrar la part de les lleudes reials de Barcelona, tant les provinents de terra com les de mar, junt amb tots els drets inherents. Però el 1303 el rei ordenà al batlle de Barcelona citar Pere Burgès o Bernat Marquet o els seus hereus, perquè volia fer-se enrera i recuperar el dret de lleuda cedit". Fou, doncs, un arranjament temporal. Tal i com indicà Jaume Sobrequés i Sebastià Riera ${ }^{12}$, la lleuda era un impost indirecte revertit damunt el comerç de productes $\mathrm{i}$ perfectament establert en el segle XII. Els productes més afectats per la lleuda eren les espècies, sobretot el pebre, l'anís i la canyella, el cotó filat, el bestiar, els esclaus i els teixits de luxe, mentre que els productes

\footnotetext{
${ }^{10}$ AMV. Pergamins secció XVII.

"ACA. Cancelleria. reg. 201, fol. 25

'2J. Sobrequés; S. Riera, La lleuda de Barcelona del segle XII, "Miscel-lània Aramon i Serra. Estudis de Llengua i Literatura Catalanes". ("Estudis Universitaris Catalans", Curial. Edicions catalanes), pp. 329-340. Barcelona. 1984.
} 
alimentaris bàsics no semblen ser-hi compresos, com si l'objectiu fos el control fiscal del gran comerç, deixant de banda el de poc significat.

L'hereu de Viladecans, Guillem Pere, també diversificà les seves operacions econòmiques però potser les coses no li anaren del tot bé perquè hagué de vendre patrimoni i també realitzà algun tripijoc que no li va sortir massa rodó. El seu testament porta la data de 9 de març de $1323^{13}$ i a través d'ell afavorí directament Jaume Burgès, fill del seu germà Arnau. Sense fills propis, la hisenda de Viladecans anà a raure a mans dels mateixos que ostentaven el títol de senyors de la Torre Burgesa.

L'hereu de Gavà, Jaume, traspassà d'hora la propietat al seu fill, Pere, que fou acusat pels pagesos de la parròquia de Gavà, davant el bisbe de Barcelona, de practicar la usura. Dels dos fills petits, Andreu i Arnau en sabem poc. Arnau tingué almenys un fill, Jaume, l'hereu de Guillem Pere, que va casar-se amb Margarida, filla de Francesca i Simó Puig, advocat de Barcelona, i arribà a Mestre Racional.

El Memorial Històric de Boscà i les Rúbriques de Bruniquer ens permeten constatar la continuïtat de la família dins el Consell Barceloní: Guillem Pere Burgès fou conseller els anys 1305, 1310, 1313, 1317 i 1318. Altres anys, com el 1314 o el 1352, fou Francesc Burgès i durant els anys més crítics de la segona meitat del segle XIV -1369, 1372, 1381, 1384figurà Jaume Burgès en les llistes dels cinc consellers en cap i també un cosí germà seu, Arnau. Eren temps especialment difícils com els mateixos consellers de Barcelona s'apressaren a manifestar l'any 1379: "(...) en consideració que lo Sr. Rey y lo Sr. Duc feyen continua residencia en Barcelona, y també per que per las mortaldats passades, y per que molts se feyen de la Casa del Rey o del senyor Duc, axi que envides se trobaba nengu qui de grat acceptás la Conselleria; per ço cresqueren lo salari a cent lliures per ditas rahons, y altras atesa la Noblesa, y la fama de aquesta Ciutat que es Cap ê principat de Catalunya..."'t

\footnotetext{
${ }^{13} \mathrm{ACB}, 4-8-81$.

${ }^{14}$ Esteve GILABERT BrUniQuer, Cerimonial dels magnifichs consellers i Regiment de la Ciutat de Barcelona, Impremta Hernich y Cia. 1913, p. 83.
} 


\section{ELS NÉTS I NÉTES DEL PATRIARCA}

La descendència del patriarca Guillem Burgès a mitjan segle XIV es trobava dividida en quatre branques: Ponç, senyor de la Torre Burgesa i el seu germà Francesc; Pere, senyor de Gavà, i Jaume, senyor de Sotarriba.

Pere, senyor de Gavà, es casà amb Antígona i de la unió tan sols eixiren dues dones: Raimunda i Graïda. Aquesta heretà el lloc de Gavà quan encara era petita i Francesc Burgès, cosí germà del seu pare, junt amb la seva muller, Francesca Grony, es comprometeren a respectar aquella donació i prometeren que quan la noia fes quinze anys li trametrien el lloc de Sant Pere de Gavà amb els seus drets, a tall de dot. I així es va fer, perquè l'any 1339 s'efectuà constitució dotal a mossèn Pere Terré ${ }^{15}$, futur marit i, d'aquesta manera, el lloc de Gavà passà a ser patrimoni d'una altra família, els Terré, fins que a principis del segle XV, els Marc, senyors del castell d'Eramprunyà des del 1323 , els ho compraren ${ }^{16}$.

Ponç fou l'altre nét que heretà la Torre Roja, per ser el més gran entre cinc germans. Era fill de Pere i era, com tots els altres, ciutadà de Barcelona, però també es considerava parroquià de Sant Climent de Llobregat. Degué tenir en força estima la seva muller, Constança, perquè no sols figura com a marmessora testamentària sinó que, a més a més, li cedí l'usdefruit de la casa situada a Barcelona, els censals derivats del dret de lleuda, una sèrie de béns mobles $i$, sobretot, el dret a disposar i prendre decisions en els negocis dels que era usufructuària, sense cap embut ni excepció ${ }^{17}$. Ponç i Constança havien tingut tres fills, Ponç, l'hereu de la Torre Roja, Joan i Maria, hereus a parts iguals del que deixava en usdefruit a la seva muller. Aquest testament datat el 23 de gener de 1385 arribava a fixar sis possibles hereus, la qual cosa, com és ben sabut, no era cap gran novetat per aquelles dates donades les característiques epidemiològiques del segle. Molt abans, un altre Burgès, Jaume, nét del patriarca Guillem i fill d'Arnau, havia testat autoanomenant-se parroquià de Sant Andreu de Llavaneres i senyor de Sotarriba, indret situat en el terme del castell de Mataró $^{18}$ l'any $1330^{19}$, tres anys abans del famós mal any primer i ja havia

\footnotetext{
${ }^{15}$ ACA, Monacals Hisenda 3510.

${ }^{16} \mathrm{ABE}$. Document 14, caixa 2.

${ }^{17} \mathrm{ACB}, 4-15-20$.

${ }^{18}$ ACA, Cancelleria, reg. 121, fol. 117.
} 
dessignat sis possibles hereus, amèn dels respectius possibles successors de cadascun d'ells; a la desesperada contemplà fins i tot la possibilitat que l'herència anés a raure a mans del seu fill il·legítim reconegut, Guillem Pere.

\section{ELS BESNÉTS ACCEDEIXEN A LA CORT}

Jaume, el senyor de Sotarriba, casat amb Margarida Puig, orientà els seus interessos molt directament cap a la Cort, apostant per la política de la casa comtal-reial d'expansió per la Mediterrània. L'any 1323, l'infant Alfons, en nom del seu pare, havia reconegut a Jaume Burgès el seu ajut en la construcció de galeres destinades a la conquesta de Sardenya i Còrsega ${ }^{20}$. Sabem que Jaume Burgès aconseguí el senyoriu de les viles o llocs de Sardenya anomenades Sibiola i Baratoli ${ }^{21}$ les quals traspassà al seu fill, també batejat amb el mateix nom.

Posseir en feu les viles esmentades comprometia Jaume Burgès a tenir disposat un cavall armat per si el monarca el precisava. Per l'agost de 1346, Guillem de Cervelló, governador i reformador de l'illa de Sardenya, es queixà de la negativa de Jaume a aportar el cavall armat que li corresponia, una obligació recordada pel propi monarca un any més tard; finalment Jaume preferí pagar mil cinc-cents sous barcelonesos per tres anys de dispensa de l'obligació i, durant aquest periode, les dues viles esdevingueren franques, lliures i immunes.

Els contactes d'aquest besnét de Guillem Burgès amb la casa reial sovintejaren, però sempre foren uns contactes com molt mercantils, amb diners pel mig: quan no era el rei qui li devia diners, era el monarca qui li recordava a ell les seves obligacions. Els contactes sempre foren de caràcter oficialista, protocolaris i freds, com quan l'any 1350 el rei Pere escriví a Rimbau de Corbera, aleshores Governador General de Sardenya i a Ramon Girona, administrador de l'illa, per fer-los saber que Jaume Burgès tenia en feu les esmentades viles $i$ insistia "ad censum unius equi armati cum quo nobis servire tenetur"22 i es certificava la percepció de rèdits procedents

\footnotetext{
${ }^{19} \mathrm{ACB}, 4-10-32$.

${ }^{20} \mathrm{ACA}$, Cancelleria, reg. 323, fol. 24.

${ }^{21}$ ACA, Cancelleria, reg. 1006, fol. 35.

"2ACA, Cancelleria, reg. 1019, fols. 163-167.
} 
dels dits llocs per la suma de 287 lliures, 12 sous i 4 diners. Igualment, segons cita Luisa d'Arienzo ${ }^{2.3}$, l'any 1355 Jaume Burgès figurava entre els cinc particulars, ciutadans de Barcelona amb interessos a Sardenya, que havien de contribuir a fer l'illa més segura ${ }^{24}$.

Un altre Burgès, Arnau, perseguí també el recer de la Corona i les seves passes s'encaminaren cap a Mallorca on aconseguí el càrrec d'escrivà de l'ofici del Mestre Racional de la Cúria Reial. L'any 1383 el monarca es dirigí a Ferrer Gilabert, Procurador Reial de Mallorca ${ }^{25}$ perquè fes un censal sobre la ciutat i regne de Mallorca del qual Arnau Burgès havia de cobrar una renda anual de pensió de 403 sous i 8 diners per un capital de 302 lliures i 15 sous.

Arnau Burgès s'havia casat amb Caterina d'origen valencià $i$ el matrimoni va tenir almenys dos fills: Arnau i Ramon. Aquest obtingué el càrrec de Camarleng per temps de cinc anys en dues viles de Sardenya i el mateix monarca, el rei Pere, li concedí el càrrec vitalici de Capità d'Alguaire de la Vila Nova, a Sardenya ${ }^{26}$.

Un altre besnét, Francesc, fill de Francesc i Francesca, s'afiançà a Barcelona. El 3 de setembre del 1393 el Dietari de l'Antic Consell Barceloní deixà registrat que havien estat varades quatre galeres de la ciutat i Francesc Burgès junt amb Francesc Ferré n'era el patró d'una d'elles. També sabem que l'any 1395 era mostassaf de Barcelona ${ }^{27}$ i que com a ciutadà honrat fou escollit Conseller l'any 1403.

\section{Els BuRgÈS EN EL CONFLICTIU SEGLE XV}

El traspàs de centúria vingué marcat pel desconcert generat per la incertesa vers la successió del comte-rei Martí, una problemàtica que complicava encara més una situació prou crítica derivada de la conflictiva política mediterrània i dels estralls demogràfics. Davant aquesta delicada

\footnotetext{
${ }^{23}$ Luisa Darienzo, Carte reali diplomatiche di Pietro IV il Cerimonioso, re d'Aragona. Riguardanti l'Italia. Padova. Cedam. 1970, vol. XIV.

${ }^{24}$ Els altres quatre ciutadans eren els hereus de Ramon Savall. Guillem Torres. Jaume Camós i Nicolau Savall de Banyoles.

${ }^{25} \mathrm{ACA}$. Cancelleria, regs. 1003. fols. 157-161; 1004, fol. 82v-83.

$2 " A C A$. Cancelleria, reg. 1034. fol. 26.

${ }^{27} \mathrm{ACA}$. Monacals Hisenda 3510.
} 
situació, el compromís de cadascuna de les famílies benestants barcelonines era inel-ludible i obligava a prendre partit i els Burgès no foren l'excepció.

A principis del segle XV la nissaga dels Burgès, descendents per línia directa de Guillem, era dividida en la branca barcelonina encapçalada pels germans Ponç i Francesc, fills de Pere, i la branca mallorquina i de Sardenya on anaren a parar els descendents d'Arnau, germà de Pere. Ja hem citat els besnéts. Jaume i Arnau, i com aquest tingué almenys dos fills: Arnau i Ramon. Aquest maridà amb Francesca, filla de Pere ça Fortesa, ciutadà mallorquí, i de la unió nasqué Gregori Burgès que reivindicà els seus drets familiars a l'hora que mirà de fer-se un nom per si mateix amb el sistema tradicional d'apropar-se a la Corona, al poder. Res més explícit que la carta escrita per la reina Maria a Berenguer de Montagut, Lloctinent i Governador del regne de Mallorca a l'agost del 1396 on ordenava que donessin quatre cavalls a Gregori Burgès perquè volia anar a lluitar contra el comte de Foix, rebel a la successió dels comtes-reis ${ }^{28}$. El passatge feia clara referència a l'episodi que tenia com a eix motor les intrigues de palau; és a dir, el complot de la reina Violant i el comte de Foix, el seu gendre, contra Martí l'Humà i la seva muller Maria de Luna. El comte de Foix, aliat amb el comte d'Empúries, envaí els dominis reials fins que el comte Pere d'Urgell els parà els peus, incorporant Empúries a la Corona. Un any més tard, el 1397. el comte-rei Martí agrai a Gregori els bons serveis prestats permetent-li fer ús de l'aigua que alimentava la ciutat de Mallorca i li deixà fer conductes per dur-la a les seves possessions amb tota llibertat.

Fins aleshores Gregori Burgès havia figurat en tots els documents com a donzell. però ja l'any 1409 Martí l'Humà s'hi referí com a miles i l'anomenà "dilectum armorum uxerum nostrum", a la vegada que li donava permís per imposar als homes del lloc de la baronia de Vallmoll tota una sèrie de gravàmens com sises de pa, vi $\mathrm{i}$ carns $^{29}$. Superats els conflictius dies del Compromís de Casp, Gregori, sempre proper a la Corona, apareixia l'any 1422 entre els ambaixadors destinats a veure el comte-rei aleshores establert a Nàpols ${ }^{30}$.

${ }^{28}$ ACA. Cancelleria, reg. 2328, fol. 88

"ACA. Cancelleria, reg. 2208. fols. 66-68.

"Dietari de la Diputació del General de Catalumya. Diputació Provincial de Barcelona. 1977. I. pp. 61-63. 
Gregori Burgès va tenir dos fills, Joan i Francesc, i dues filles, Isabel i Caterina, però els quatre foren fruit d'unions il-lícites. Donada la il·legalitat de la situació, Gregori sol-licità de la Cort la legitimació dels seus fills naturals, una legalització que comptà amb el suport de la reina Maria sempre deixant clar que, si hi havia fills o filles de caràcter legítim, aquests o aquestes tindrien prioritat davant els altres.

Francesc Burgès, senyor de Viladecans, fou escollit el 31 de maig de 1410 per anar en nom de la ciutat de Barcelona, a veure al Comte d'Urgell que era a Aragó i el 16 d'agost del 1411 fou comissionat pel Governador General del Principat, Guerau Alamany de Cervelló, perquè obrís la sessió del Parlament català que es trobava reunit en minoria a Tortosa i fes pròrroga del mateix, però la proposta no fou acceptada i els tres braços s'oposaren al nomenament d'adjunt fet pel Governador en la persona de Francesc Burgès. Santiago Sobrequés ${ }^{31}$ defensà que durant els primers quinze mesos de l'interregne, almenys fins a l'estiu de 1411, la majoria del Parlament català es decantà per Jaume d'Urgell, modificant-se la situació quan, passat l'estiu i traslladat el Parlament a Tortosa, la burgesia i l'església escolliren per altra banda, mentre que la cavalleria antiurgellista només acollia un petit nombre de personatges. El mateix historiador sense menystenir les tesis de Ferran Soldevila o de Joan Reglà, insisteix en accentuar com a perjudici veritable per al candidat urgellista la demora en la decisió, una demora no imputable a la cavalleria sinó a una maniobra política/dilatòria de la minoria francòfila. I, com una demostració més, recorda que el 30 de setembre de 1410 quan s'inaugurà el Parlament i Ramon de Sentmenat, Gregori Burgès, Berenguer de Malla i Guerau de Sanahuja presentaren una cèdula en nom del Braç reyal dels cavallers $e$ hòmens de paratge per la que s'adherien a la protesta feta pel fill del comte de Pallars, queixant-se pel trasllat del Parlament de Montblanc a Barcelona, Francesc Burgès i Guillem Domenge, síndics, junt a altres del seu braç reyal de les ciutats $i$ viles reials protestaren i digueren al Governador que no consentirien de cap manera que els cavallers i homes de paratge formessin un braç independent del de la noblesa on s'encabien.

Ponç Burgès, senyor de la Torre Burgesa, tingué una actuació més discreta. Continuador del nom per tercera generació consecutiva, el Consell

\footnotetext{
"Santiago SOBREQUÉS I VIDAL. La petita noblesa catalana i l'interregne de 1410-1412. "Estudis d'Ilistoria Medieval". 3 (1973), pp. 87-110.
} 
de Cent de Barcelona li atorgà la responsabilitat d'administrador del pont de Sant Boi l'any 1423. Sense descendència directa, féu hereu al seu nebot Joan que testà l'any 1466 deixant una filla anomenada Elisabet.

L'ascens de Ferran de Trastàmara i el regnat del seu successor, Alfons el Magnànim, amb el seu interès per les terres de la Mediterrània, no alterà per a res la posició de la familia Burgès, afilarada, com d'habitual, pel cantó de la monarquia. No sabem de cert si els Burgès actuaren de manera directa en l'expedició dirigida pel comte-rei Alfons contra Sardenya el 1420 cercant la pacificació de l'illa, al temps que maldava per aconseguir l'expulsió definitiva dels genovesos. Els afers conduïren a l'empresonament del comte-rei Alfons junt a nombrosa noblesa i burgesia barcelonina. Però, alliberat, tornà al seu objectiu inicial, la cobejada ciutat de Nàpols on entrà triomfalment el 2 de juny de 1442. Dos anys més tard, Galceran Burgès de Sant Climent rebia una mostra del reconeixement reial a través de la ratificació de privilegi concedida temps enrera per Jaume I als senyors de Viladecans, Gavà i Torre Roja; el comte-rei feia al·lusió expressa al reconeiximent de serveis portats a terme per Galceran i s'apressava a ratificar el poder jurisdiccional concedit pel seu avantpassat a Guillem Burgès.

Galceran Burgès de Sant Climent, senyor de la Torre Roja i fill de Francesc Burgès i Margarida de Sant Climent, arribà a ostentar el càrrec de Veguer de Barcelona i passà no poques penalitats enmig d'aquesta lluita entre poders i pel conflicte que enfrontà les institucions catalanes amb Joan II. Ja l'any 1452 el seu fill, junt a Bernat Guillem, abat d'Ager i mossèn Berenguer de Montpalau, fou escollit Diputat del General de Catalunya per temps de tres anys ${ }^{32}$. Novament el seu nom torna a sortir com a part integrant de l'ambaixada de divuit diputats que junt a sis ambaixadors escollits per Carles de Viana havien d'anar a veure la reina Joana per mirar de "cobrar resposta definitiva d'och o de no, si lo senyor rey fermara certs capitols de que la terra l'a suplicat".

Aquesta ambaixada, acordada el 27 de maig de 1461, fou posterior a una altra de 8 de desembre de 1460, any de la concòrdia de Barcelona, on Galceran Burgès de Sant Climent hi tingué un paper destacat com un dels 27 consellers que estaven a l'aguait dels moviments tàctics amb el monarca. La

\footnotetext{
${ }^{32}$ Manual de novells ardits, rulgarment apellat dietari del antich consell barceloni, ed. per Frederich Schwartz i Francesch Carreras. I. Barcelona. 1892. p. 202.
} 
mort de Carles de Viana, les històries difoses on s'acusava Joan II d'haver ordenat emmetzinar el seu propi fill, els fets miraculosos atribuïts al primogènit, els enfrontaments entre la reina i els consellers, una població exaltada $\mathrm{i}$ fàcil de manipular convertí Barcelona en una ciutat insegura $\mathrm{i}$ perillosa. Fou en aquest context que els funerals per Carles de Viana celebrats el 5 d'octubre de 1461 acabaren de crispar els ànims i deu dies més tard, el 15 d'octubre, Galceran Burgès contemplà com incendiaven la seva casa.

\footnotetext{
A gran hora de nit, alguns mals hòmens, poch taments de Déu e de la correció de la senyoria terrenal. materen foch a les portes de casa del honorable mossèn Galceran Burgues, qui sta al carrer Ample. El dia 20. fonch feta crida en la ciutat de Barchinona de part dels honorables vaguer e batle de la dicta ciutat. e a instancia dels consellers. contenent en efecte que. tothom qui denunciàs qui havia mes foc a les portes de la casa de mossèn Galceran Burguès li serien dats 100 florins d'or e si-m denunciava algú d aquells qui y són stats. pus no fos lo principal, li seria feta remissió. però aquest tal no hauria los dits 100 florins... ${ }^{33}$
}

Dos mesos més tard a aquests fets, el 2 de desembre, Galceran Burgès i de Sant Climent prenia el bastó de Veguer de Barcelona en un intent per compensar-lo de les malvestats sofertes. Tanmateix, però, el càrrec no li fou massa favorable. La reina, copsant la delicada situació i l'empenta cada cop més forta de la Biga, decidí d'anar-se'n cap a Girona però ordenà al cavaller Galceran Burgès que, com a veguer, li enviés còpia de totes les investigacions i persecucions que es duessin a terme. Carme Batlle subratllà les dificultats de Galceran per complir la comesa davant els impediments posats pels consellers de la Busca que el destituïren, li tregueren el bastó de comandament i l'empresonaren obrint-li un procés. confiscant-li els béns i ensorrant la seva casa ${ }^{3+}$.

Segons Melcior Miralles ${ }^{35}$, clergue valencià i capellà d'Alfons el Magnànim, els fets tingueren un culpable anomenat Perdigó que era conseller. Segons conta, mentre la reina i el seu fill Ferran eren a Girona,

\footnotetext{
"Manual de novells ardits. I.

${ }^{3}$ Carme Batlle. La crisis social y económica de Barcelona a mediados del siglo XV. 2 vols.. Universitat de Barcelona. 1973, p. 178.

:Melcior Miralles. Dietari dei capellà d'Alfons el Magnämim. Ed. Alfons el Magnànim. Institució valenciana destudis $\mathrm{i}$ investigació. València. 1989.
} 
els enfrontaments entre els partits de la Busca i la Biga pujaven més i més de to i Perdigó, empresonat i posat a torment per elements de la Busca, denuncià Galceran Burgès de protegir els interessos de la reina més que no pas els de Barcelona.

El seguit de malestrugances de Galceran Burgès serien compensades per la monarquia per mitjà del seus fills. L'any 1469 el rei Joan II concedí a Francesc Burgès de Sant Climent, per la seva fidelitat durant la guerra civil, uns béns confiscats a Bernat de Gualbes, enemic del rei ${ }^{36}$. L'escrit feia referència a les penalitats i requisa de patrimoni suportades per Galceran per raó de la seva fidelitat incondicional, de manera que la Corona volia gratificar aquells esforços i Joan II donà cinquanta lliures anuals, moneda de Barcelona, a Francesc Burgès, una quantitat procedent dels béns de Mallorca de Bernat de Gualbes, difunt, i que foren anorreats a la seva mare. Tot $\mathrm{i}$ així, Francesc Burgès no es donà per satisfet i l'any 1472 es dirigí al monarca en els termes següents:

Senyor molt alt e excellent. En Francesch Burguès suplica a vostra excellència que en remuneració dels tants serveys que ha fets e prestats $\mathrm{e}$ fer e prestar no cessa a vostra Magestat e encara en alguna satisfacció dels dans que ha reebuts e li són stats fets per los rebelles e inobedients barcelonins e altres que ni han pres e occupat quasi e la major part de sos béns e heretatge, sia mercè vostra ferli gràcia e donació a ell e als seus del castell de Plegamans, termes, vassalls, heretats e béns mobles e seents del dit castell de Plegamans qui fou pertanyent o pertanyerien a mossèn Anthoni de Vilatorta, stant en Barcelona, rebelle e inobedient a vostra excellència, qui és hu de aquells qui han occupats los béns e heretatge del dit Francesc Burguès... ${ }^{37}$

El rei li ho concedí i encara hi afegí quelcom més: a dotze d'octubre del mateix any li féu mercè de la jurisdicció civil i criminal i del mer i mixt imperi de Viladecans i del seu terme ${ }^{38}$, contemplant una penalització de tres mil florins d'or si algú no respectava la concessió.

Francesc Burgès de Sant Climent instituí hereu universal al seu fill Bartomeu, seguit, en drets, pels altres fills: Galceran, Gaspar i Leonor Angela.

\footnotetext{
${ }^{36} \mathrm{ACA}$, Cancelleria, reg. 3449, fols. 110-111v.

${ }^{37} \mathrm{ACA}$, Cancelleria, reg. 3388, fols. 184-185.

${ }^{38} \mathrm{ACA}$. Cancelleria, reg. 3388, fols. 184-185.
} 
La sort de la branca familiar, l'establerta a Mallorca, mereix també ésser considerada. Francesc Burgès, cavaller, ciutadà de Mallorca i hereu del càrrec patern de Camarleng, també s'havia posicionat en el cantó reial quan el conflicte bèl-lic, com ho mostra l'escrit de l'any 1458 adreçat per Joan II al Governador i Lloctinent de Mallorca requerint l'introduís dins l'ofici de Regent de la Procuradoria Reial del Regne de Mallorca en substitució de Joan Albertí per "la probitat, fidelitat e sinceritat del qual es a nos de loch temps ença manifesta"39.

Francesc Burgès saltà de Camarleng a Procurador Reial de Mallorca, càrrec que acabà passant de pares a fills. Francesc obtingué, a més de la dignitat esmentada, un sucós patrimoni per directa donació reial. Joan II li traspassà censals $\mathrm{i}$ rèdits que fins aleshores corresponien a altres persones però que els havien estat expoliats per haver donat suport al sector perdedor $^{40}$ fins un muntant de 499 lliures, 13 sous i 8 diners. Només un any més tard, el monarca tornava a concedir prebendes a la família fent concessió a Bernat Burgès, àlies ça Fortesa, de tots els béns i heretats de Joan Pons i la seva muller, matrimoni declarat en rebel-lia contra el monarca ${ }^{41}$. Termes similars tornaren a emprar-se per a Pere Burgès, àlies ça Fortesa i Arnau Burgès, àlies ça Fortesa. Totes les donacions reials es localitzaven a Mahó i mentre Pere rebia el que s'havia confiscat a Llorenç Pons i a Pere Huguet, Arnau es quedà amb l'heretat de Montserrat Juneda.

Francesc Burgès emancipà el seu fill Gregori Burgès, donzell, habitant en el Principat de Catalunya l'any $1455^{42}$ i el 1458 Gregori aconseguia de la casa reial una sentència favorable davant el plet contra Lluís de Perelló pels drets i possessions del lloc de Sant Feliu Damunt i de Sant Feliu Davall ${ }^{43}$, localitats situades al comtat del Rosselló. Gregori, com hereu del seu pare, obtingué el nomenament de Cònsol de la ciutat de Mallorca i el 1479 Ferran II li reconegué la castlania de Sanctuyri, del regne de Mallorca, en atenció als nombrosos perills encarats ${ }^{44}$. Però, sens dubte, el reconeixement més meritori fou la concessió de noblesa que obtingué del

\footnotetext{
${ }^{39}$ ACA. Cancelleria, reg. 3435, fols. 169v-177.

${ }^{40} \mathrm{ACA}$, Cancelleria, reg. 3445 , fol $172 \mathrm{v}-174$.

${ }^{4} A C A$, Cancelleria, reg. 3445, fol. 33-33v. i 70v.-72v.

${ }^{42} \mathrm{ACA}$, Cancelleria, reg. 3297, fol 150v.; reg. 3309, fol 138-140.

${ }^{43} \mathrm{ACA}$, Cancelleria, reg. 3361, fols. 4v-5.

${ }^{44} \mathrm{ACA}$, Cancelleria, reg. 3636, fol. 182-183v.
} 
monarca l'any $1488^{45}$. L'escrit recordava com la noblesa ja li provenia de part de mare però, tot i així, s'incrementava pels mèrits acumulats per la pròpia actuació i se subratllava com en edat primerenca el xicot ja havia defensat la Corona a la fortalesa de Girona contra els enemics, i també com havia acudit a la guerra de Granada. Per tant, tant pels mèrits passats com els que eren de preveure en un futur, Ferran II li atorgava en caràcter hereditari, per línia masculina directa, títol de noblesa.

El darrer testimoni recollit d'aquesta branca mallorquina i de la seva puixança, correspon a mitjan segle XVI i és el testament de Joana d'Erill, vídua de Francesc Burgès, Procurador Reial de Mallorca i fill de Gregori ${ }^{46}$. Joana era filla dels nobles Pedro de Erill, baró d'Erill, i d'Elena Recasens i les seves germanes eren la marquesa de Boixadors, la muller del Condestable don Pere de Cardona i la muller de Jaume de Sentmenat. Tanmateix, però, el matrimoni entre Francesc Burgès i Joana no tingué descendència, ells concloien la branca mallorquina des que uns tres-cents anys abans, Guillem Burgès, el patriarca mercader, havia reunit i redistribuït el seu patrimoni.

\section{Els darrers Burgès de Sant Climent}

A efectes de patrimoni i nom, la branca barcelonina dels Burgès havia estat força desafortunada. La línia de Ponç Burgès, senyor de la Torre Roja, s'havia trasmès a través d'Elisabet que havia tingut un fill anomenat Joanot de la Riba perdent-se, per tant, el cognom Burgès per aquesta branca familiar. Joanot decidí vendre la Torre Burgesa a l'advocat Esteve Salavardenya l'any 1527.

Mentrestant Viladecans era a mans de Francesc Burgès de Sant Climent que dedicà una part important de la seva vida a cobrar els rèdits de la contesa militar catalana segons mostra una documentació que sempre versa entorn els mateixos temes: reivindicació de drets, demanda de privilegis, queixes i plets com el que involucrà a Cassà de la Selva que li pagava un censal. Els parroquians de Cassà es negaren a satisfer les pretensions de la família Burgès adduint que no hi havia constància documental; portat el

\footnotetext{
${ }^{45} \mathrm{ACA}$, Cancelleria, reg. 3621, fols. 78v-80.

${ }^{16}$ AHPNB, Notari Onofre Bou. Pliego testamentario. Varios años. Lligall 16.
} 
conflicte a tribunals es dictà sentència favorable per als Burgès, aleshores ja Galceran, però els pobladors de Cassà demanaren revisió del dictat ${ }^{47}$ que perderen una altra vegada ${ }^{48}$.

Galceran Burgès també passà comptes al propi Ferran II i el monarca ordenà l'any 1506 de pagar-li la quantitat de cent florins d'or per satisfer el preu d'un cavall comprat l'any $1478^{49}$. Tot i aquestes cuites, Galceran Burgès seguí la tradició familiar de buscar acollida a recer de la monarquia i el 1509 el trobem com a oydor del stament militar.

Galceran casà amb Àngela Aleixa i de la unió en nasqué un nen batejat també amb el nom del pare. El nou Galceran fou qui prengué la decisió de vendre Viladecans a Joan Agullana, ciutadà de Girona i Barcelo$\mathrm{na}^{50}$. Aquesta venda significava la fi de la presència dels Burgès en el terme baix-oriental d'Eramprunyà després d'una presència ininterrompuda a través de tres-cents anys i després d'haver estat els únics que any rera any, duts per una constància encomiable, havien aconseguit aturar els peus dels autèntics senyors del territori durant la Baixa Edat Mitjana, els Marc.

Tanmateix podem encara resseguir què fou d'aquesta família. El darrer Galceran Burgès s'havia maridat amb Isabel de So, filla de Bernat de So, domiciliat a Cervera, que havia portat al matrimoni els termes i llocs de Talavera i Pavia, de la vegueria de Cervera i bisbat de Vic. El matrimoni va tenir un fill, Joan, i dues filles. L'any 1582 Galceran Burgès i de Sant Climent, domiciliat en el barri de Santa Maria del Mar, féu testament ${ }^{51}$ mentre el seu fill s'havia maridat amb Anna de Ivorra, filla de Bernat Joan de Ivorra, ciutadà de Barcelona i castlà de la Guardiallada, de la vegueria de Cervera. Els capítols matrimonials previs al casori havien corroborat la donació paterna dels llocs, termes i castells de Talavera i Pavia, inclosa la jurisdicció civil i criminal, alta i baixa, però pare i mare en retenien l'usdefruit mentre visquessin; mentrestant, com a compensació, li oferien

\footnotetext{
${ }^{47}$ ACA, Cancelleria, reg. 3844, fols. 124-125.

${ }^{48} \mathrm{ACA}$, Cancelleria, reg. 3555 , fol. 188.

${ }^{49} \mathrm{ACA}$, Cancelleria, reg. 3555, fol. 188.

${ }^{50} \mathrm{ACA}$, Monacals-Hisenda 3510.

${ }^{51}$ AHPNB, Notari Lluís Jorba (menor), Secundus Liber Tetamentorum. Anys 1575-1603,
} fol $30 \mathrm{v}^{\circ}$. 
1.000 ducats. La núvia, per la seva banda, es beneficiava d'un dot de 4.000 lliures, resultat dels beneficis derivats de diversos censals ${ }^{52}$.

Anna de Ivorra morí abans que Joan Burgès i aquest tornà a casar-se i ho féu amb Victòria de Paguera. Joan aconseguí del rei Felip II el títol de noblesa, doncs el monarca li concedí l'any 1586 el dret a autoproclamar-se baró de Talavera ${ }^{53}$. Per voluntat testamentària $a^{54}$, el darrer Burgès que per línia directa de primogenitura descendia del mercader Guillem Burgès, féu hereu universal a Ramon Blanes i de Centelles sota el pacte que, de les rendes totals de les seves propietats, havia de fer-ne tres parts: una part havia de cedir-la als administradors de l'Hospital de la Santa Creu, una altra part havia d'anar a raure a mans de Miquel Pons i Turull i la tercera part havia d'ésser per al propi Ramon. Joan Burgès, conscient de la feina que pertocava al pressumpte hereu per endegar totes les seves disposicions, li féu llegat particular de la prerrogativa de la capella i de la casa situada en lo carrer dels mercaders.

\section{RÉSUMÉ}

La lecture de cet article nous introduit dans une famille très nombreuse, les Burgès, seigneurs de Viladecans i Gavà (contrée du Baix Llobregat) depuis la moitié du XIII siècle. C'est une famille dont la vie et l'évolution sont représentatives de beaucoup d'autres de son époque, avec les mêmes aspirations, des ambitions et des luttes pour se frayer un chemin dans la société de Barcelone du bas Moyen-Âge. L'étude de ce procès nous semble spécialement intéressant parce qu'on a pu faire l'analyse des différentes stratégies utilisées pour accéder au pouvoir économique et à une meilleure considération sociale. Depuis leurs premiers temps c'était une famille de marchands qui, très tôt, avait fait alterner les affaires commerciales avec celles des propriétés immobiliaires et rustiques, ayant comme but le rapprochement de la Couronne. La famille Burgès, dispersée dans les domaines de la Couronne d'Aragon, mais unie pour donner son appui et son aide aux moments difficiles de la guerre entre Jean II et la Generalitat, obtint ainsi la protection définitive de la monarchie.

\footnotetext{
${ }^{52}$ Es dóna la circumstància que un d'aquests censals afectava directament al senyor de la baronia d'Eramprunyà, Hug de Palou. Era un censal de 1.100 lliures, heretat de l'època dels Marc i que originava 39 lliures, 5 sous i 8 diners de pensió anual.

${ }^{53} \mathrm{ACA}$, Cancelleria, reg. 4316, fols. 140-142.

${ }^{54} \mathrm{BC}$, Arxiu Moia, Lligall 97.
} 


\section{SUMMARY}

The main characters of the present article are the members of the extensive Burgès family, lords of Viladecans and Gavà (in the Baix Llobregat area) from the middle of the 13th century. This family stands for many others, since its evolution over the years mirrors similar wishes and fights for thriving in the Barcelona of the Low Middle Ages. The study of this process is of special interest because it allows for the analysis of different devices used in gaining more economic benefit and better social consideration. Traders at the beginning, the Burgès family soon combined trade and the managing of rural state properties, under the shelter of the Crown. This shelter would become permanent from the moment in which the whole family -in spite of being scattered all over the lands belonging to the Crown of Aragón- supported the monarchy during the war which confronted Joan II with the Generalitat. 